\title{
Comparison of porosity models for fluidized beds
}

\author{
Sherko Ahmed Flamarz \\ Sulaimani Polytechnic University, \\ Sulaimani, Iraq \\ Sherko.flamarz@spu.edu.iq
}

\begin{abstract}
The paper describes a comparison between four numerical models of porosity, for better understanding the influence of porosity on the hydrodynamics (macroscopic and microscopic) behaviors of fluidized beds. The study has been done through an approach based on combine discretecontinuum to achieve the simulations. This approach deals with the modeling of the interactions between the fluid-solid. In which the discrete approach is used for localizing the position and velocity of each individual particles based on Newton's $2^{\text {nd }}$ law of motion, using a numerical time stepping scheme. While the continuum approach is based on finite volume method, which is solved the fluid flow equations (Navier-Stokes equations). The geometry of fluidizing column was; column diameter $(D=0.096 \mathrm{~m})$ and column height $(H=1$ m). Glass grains were firstly deposited inside the column, and then subjected to the range of inlet water velocity $\left(0-0.14 \mathrm{~m} \cdot \mathrm{s}^{-1}\right)$. The results of simulations are point out those four models of porosity, achieved comparable results for simulating fluidized beds. The simulations results were compared and showed a good agreement and consistency with the experimental data in the literatures. In other hand, the simulations results revealed that the models of porosity, which based on the microscopic scale, are most reliable between the models of porosity. However the differences between these models must be analyzed and kept in mind in order to select the appropriate porosity model. The results revealed that the porosity is an important parameter which effect on the hydrodynamics behavior of fluidized beds during the fluidization processes.
\end{abstract}

Keywords: Numerical simulation; Porosity; Fluid-solid flow; Discrete approach; Continuum approach; Circulating fluidized bed.

\section{INTRODUCTION}

Many of industrial applications include of two phase flow (solid phase and fluid phase). Processes like fluidization, pneumatic transport, spouted beds, sedimentation, etc. In each of those processes, it is an important fact to reach a homogeneous distribution for the solid phase. Although it is not possible to obtain homogeneity for the solid phase in the whole of the bed, then it is pivotal to know the intensity distribution of the solid phase in various parts of the system to predict the behavior of the solid phase in the processes. The solid phase (solid particles) distribution or concentration is called porosity or bed voidage $(\varepsilon)$ which is represent the ratio of volume taken by fluid to the total volume occupied by solid particles and the fluid. The porosity is main factors in describe and characterize the hydrodynamics behavior, heat and mass transfer properties of fluid-fluidized beds. In the case of spherical particles the porosity can vary between $(\varepsilon=0.476)$ in case of a stationary bed, up to $(\varepsilon=1)$ which the last solid particle has been removed from the volume of the system (apparatus).

\section{LITERATURE REVIEW}

A number of different studies and researches are achieved to understand the act of porosity (bed voidage) on the hydrodynamics of two phase flow. Different experimental methods are developed for observation and measurement of the bed porosity allocation in fluidization processes. Methods of measurements can generally be divided into mechanical, pressure, electrical capacitance and optical methods. According to the processes, the measurements can be divided into local, zone and averaged over a part or all the bed [1, 13]. Although of certain limitations of experimental techniques (experimental instrumentations and measurement methodology), but experimental techniques have provided valuable information on concentration (porosity) of solid phase in fluid-fluidized beds. Mathematical (theoretical) models are proposed for predicting the solid concentration profile in fluidized beds [14- 17]. The lacks in mathematical models are still need to experimental validation for fluidized systems. In other hand, empirical studies have been made for understand the macroscopic behavior of fluidized beds. Gidaspow and Ettehadieh [18] have proposed the first computational approach model to estimate the porosity distributions for 2D fluidized bed. Bouillard et al. $[10,19]$ have studied and extensive the experimental and theoretical work by proposing a model to study the fluidization process in a two-dimensional bed. In recent years, with the progress in calculation capacities pushed the computational models to develop and reproduce mechanical behaviors in macroscopic and microscopic levels, of complex units involving multiphase flows. Many of models have been studied circulated fluidized beds and proposed some models of porosity as secondarily in their researches [20-25]. Tanaka et al. [26] investigated the cluster formation in a circulating fluidization in gas-solid flows, and the effect of global porosity on the inhomogeneous and stability of the system. Helland et al. [27-31] have been studied the effects of the porosity on the value of the drag force, through the formation of cluster in circulating fluidized beds. It can be noted that pure researches of porosity is rare in numeric side and still in experimental works depends on the visual (macroscopic), thus the 
motivations of present work are; present four numerical models of porosity, for examination and prediction the hydrodynamics macroscopic and microscopic behaviors of fluidized beds, applying a combine discretecontinuum approach to achieve the simulations, numerical results of a fluidized bed simulation will present and compare to experimental results, in order to select the appropriate porosity model, and optimize the hydrodynamics behavior of fluidized beds through a porosity model, and used it as dependable design tool for fluidized beds systems.

\section{METHODS AND MATERIALS}

\subsection{Numerical Method}

In order to describe the hydrodynamic characteristics of fluidized beds, these must related to the porosity, particle size, and physical properties for the fluid and the particles. Four models of porosity are tested through a combine of discrete-continuum. This combine is provided an effective method for numerical simulations of fluid-solid fluidized beds. In continuum approach, the fluid phase is evolved in the computational fluid dynamics (CFD) system, and the solid phase is treated by the discrete approach (DEM) [32-35].

\subsection{Discrete approach model}

The originality of the discrete element code (SIGRAME) consists in using as contact solver the bipotential initiated by de Saxcé [36]. In a fluidized bed system, consists of $N$ particles, the maximum number of contacts between the particles is an important parameter in numerical modeling. The discrete code SIGRAME which is house code uses the separating method combined with connectivity table [37]. This combined is reducing the cycle of calculation time. Moreover, it uses the NSCD concept developed by Jean and J.-J Moreau $[38,39]$, which allows to model correctly the dynamic effects but also to work with a step of discretization $\left(\Delta t \approx 10^{-3} s\right)$ in comparison with the explicit codes $\left(\Delta t \approx 10^{-7} s\right.$ ). In the present study, the particles are spherical non-deformable and non-penetrable. By choosing $q$ as parameters of configuration, the coordinates of the center of gravity of the particles. The mechanical equation to be modeled is in the following:

$M \ddot{q}=F_{e x t}(q, \dot{q}, t)+R^{\alpha}$

where $F_{\text {ext }}$ represent the known external forces and $R^{\alpha}$ is the unknown internal forces associated with unknown prior contact reactions. Each couple of particles $i$ and $j$ which are candidates for contact (Figure1), the local reaction $F_{C}$ (contact force) is given by:

$$
F_{C}=F_{t}+F_{n} \cdot n
$$

where $n$ is the normal unit vector from particle $j$ to particle $i, F_{t}$ is the friction force and $F_{n}$ is the normal force. The algorithm of calculation cycle is using a numerical time stepping scheme.

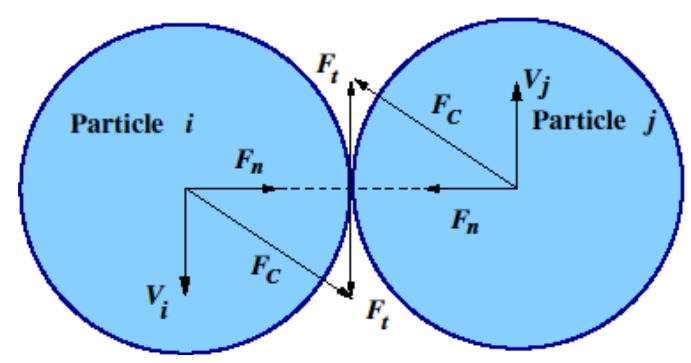

Figure1 Contact force between two particles

The movement of each particle is governed by the laws of Newton's second law of motion, for $i$-th particle, by:

$m_{i} \frac{d v_{i}}{d t}=m_{i} g+F_{C, i}+F_{B, i}+F_{D, i}$
$I_{i} \frac{d \omega_{i}}{d t}=T_{i} \quad$ and $\quad I_{i}=\frac{2}{5} m_{i} r_{i}^{2}$

where $m_{i}$ represent mass,,$r_{i}$ is the radius, and $v_{i}$ is the velocity of the $i$-th particle, $g$ is acceleration due to gravity, $F_{C, i}$ is the contact force between the particles which is calculated by the discrete code, $F_{B, i}$ is the float (buoyancy) force, $F_{D, i}$ is the $\operatorname{drag}$ force, $I_{i}$ is the moment of inertia and $\omega_{i}$ is the angular velocity of $i$-th particle, $T_{i}$ is the torque. The particle-fluid drag force (Di Felice drag force model) [40] is obtained from:

$F_{D, i}=0.125 C_{D, i} \pi d_{i}^{2} \rho_{f}\left|v_{f}-v_{i}\right|\left(v_{f}-v_{i}\right) \varepsilon_{i}^{1-\chi}$

where $C_{D, i}$ is the drag coefficient of the fluid on the particle $i, d_{i}, \varepsilon_{i}$ are the diameter and porosity of the particle $i, \rho_{f}, v_{f}$ are the density and velocity of the fluid. $\varepsilon_{i}^{-\chi}$ is the corrective function to take in account the presence of other particles in neighbors of the particle $i$ in to consideration, and $\chi$ is empirical coefficient can expressed as;

$\chi=3.7-0.65 \exp \left[\frac{-\left(1.5-\log _{10} R_{i}\right)^{2}}{2}\right]$

where $R e_{i}=\rho_{f} \varepsilon_{i}\left|v_{f}-v_{i}\right| d_{i} / \mu_{f} \quad$ is the particle Reynolds number, the drag force coefficient $\left(C_{D, i}\right)$ is implemented in the combine model as (Brown and Lawler)

[41]:

$$
C_{D, i}=\frac{24}{R e_{i}}\left(1+0.15 R e_{i}^{0.681}\right)+\frac{0.407}{1+\frac{8710}{R e_{i}}}
$$




\subsection{Continuum approach model}

The continuum approach (Computational Fluid Dynamics (CFD)) has developed in last two decades with the increase of capacity of the computers. The CFD codes are able to solve the governing equations of fluid flow for laminar and/or turbulent flows [35]. In this study, the CFD code is code_Saturne (version 3.0) and Salome platform (version 7) for design the geometry of the case study. The code is open source CFD software developed by EDF of France, the code is based on finite volume method which solves the Navier-Stokes equations for $2 \mathrm{D}$ and $3 \mathrm{D}$ flows. The code accepts meshes with any type of cell (tetrahedral, hexahedral, polyhedral ...) and any type of grid (structured, unstructured, hybrid ...). The locally-averaged continuity and Navier-Stokes equations (pressure-velocity coupling) are solved by SIMPLEC method [42]. The assumptions were no slip boundaries and unstructured meshes are used for the column walls in the CFD model. The $k-\varepsilon$ model is used in this work, which largely applied for its simplicity.

The mass balance and the momentum balance of the fluid gives:

$$
\begin{aligned}
& \frac{\partial \rho_{f}}{\partial t}+\nabla \cdot\left(\rho_{f} v_{f}\right)=0 \\
& \frac{\partial\left(\rho_{f} v_{f}\right)}{\partial t}+\nabla \cdot\left(\rho_{f} v_{f} \otimes v_{f}\right)=-\nabla \cdot p_{f}+\nabla \tau+\rho_{f} f
\end{aligned}
$$

where $\rho_{f}, p_{f}, v_{f}$ represents density, pressure, and velocity of the fluid flow respectively, $t$ denotes the time, $\tau$ is fluid viscous stress tensor and $f$ is the gravity force.

\subsection{Combine Discrete-continuum (CFD-DEM)}

The calculation by the CFD allows us to obtain the field of velocity in every knot of the mesh $M$. The technique to calculate the speed of every particle $p$ decomposes into 2 stages:

i) look what is the element $e$ of $M$ which contains the particle $p$

ii) calculate the speed of the particle $p$ from the speeds of the knots of the element $e$ :

$v_{p}=\sum_{j=1}^{n e} \varphi_{j, p} v_{j}$

where $\varphi_{j}$ denotes the basic functions calculated in the center of the particle $p, n e$ is the number of the nodes in the element. The calculated speed is used to compute the drag force on the particle. To optimize the calculation time, table of inverse connection is build. The search for the knot $i$ of the meshing $M$ the closest of $p$ so allows, from the table of inverse connection, to look for the element $e$ only on the patch of elements connected in $i$ and not on all the elements of $M$ (Figure 2).

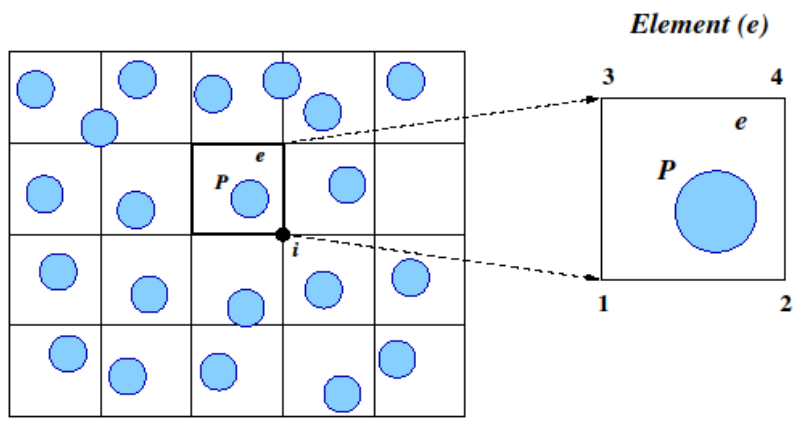

Figure 2 Sketch of particles in mesh arrangement

\subsection{Models of porosity}

The porosity in the vicinity (neighborhood) of each particle is estimated according to 4 models that will be comparing;

- First model (Mod1) is defined by:

$\varepsilon=1-0,131 N_{b}$ if $N_{b} \leq 4 ;$ otherwise $\varepsilon=0,476$

where $N_{b}$ represent the number of contacts of the particle, the value of $\varepsilon=0,476$ corresponds to the porosity of a sphere in a cube [29].

- Second model (Mod2) is defined by:

$\varepsilon=\frac{V_{\text {max }}-V_{p, T}}{V_{\max }}$

where $V_{\text {max }}$ is the volume defined by the height of the highest particle in the fluidized bed, and $V_{p, T}$ is the total volume of the particles [16].

- Third model (Mod3) which uses the mesh $M$ serving for the detection of the contacts is defined by:

$\varepsilon=\frac{V_{e}-V_{p, e}}{V_{e}}$

where $V_{e}$ is the volume of the mesh $e$ containing the particle and $V_{p, e}$ is the volume of the particles contained in the mesh [43].

- Fourth model (Mod4) calculates a local porosity from a REV (Representative Elemental Volume) around each particle, detailed in [35]:

$\varepsilon=\frac{V_{R E V}-V_{p, R E V}}{V_{R E V}}$

where $V_{R E V}$ is the volume of the REV and $V_{p, R E V}$ is the volumes of the particles in the REV. The calculation of the porosity in models 3 and 4 requires the calculation of the volume of grains contained in a mesh or a REV; this can be obtained by the following formula: 


$$
V_{p, R E V}=\sum_{j} \frac{4}{3} \pi a_{j}\left\langle a_{j}-\left\langle h_{x}\right\rangle_{+}\right\rangle_{+}\left\langle a_{j}-\left\langle h_{y}\right\rangle_{+}\right\rangle_{+}
$$

where $\langle\cdot\rangle_{+}$represents the positive part, $h_{x}$ and $h_{y}$ are the deviations between the center of the particle $j$ of radius $a_{j}$ and the edges of the REV (Figure 3).

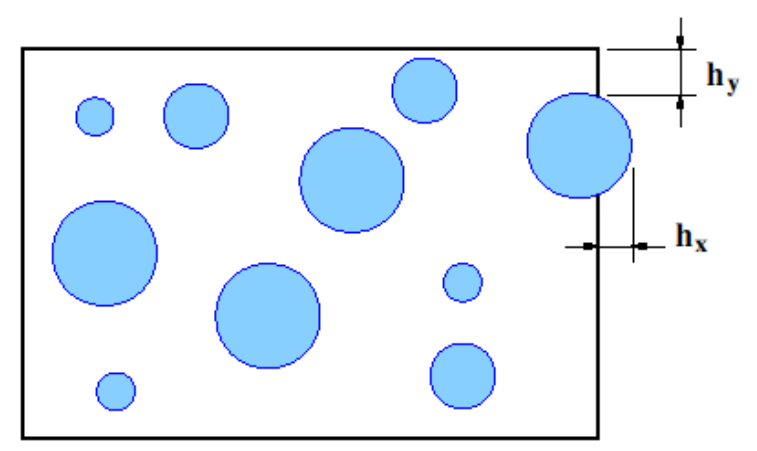

Figure 3 Sketch of REV

\section{Results and discussion}

The hydrodynamic characteristics of fluidized beds including porosity (bed voidage) and bed height were investigated for fluidized beds. The geometry of fluidizing column (pipe) has the dimensions $(\mathrm{D}=0.096$ $\mathrm{m}, \mathrm{H}=1 \mathrm{~m}$ ), as depicted in (Fig.4-a,b), to compare the performance and affectivity of the four models of porosity. Glass grains were firstly generated and deposited inside the column under gravity, see Table 1, and then subjected to the flowing water. Non slip boundaries are used for the column walls in the CFD model. The numerical parameters employed are listed in Table 1. The CFD model consist of unstructural mesh with; 944 tetrahedron elements, 369 nodes, 69 edges, and 2470 triangles (Fig.4-c).

\subsection{Porosity (bed voidage)}

Figure 5 (a-f), shows the fluidized bed porosity for the four models as a function of time of simulation for a range of inlet water velocity. Figure 5-a, depicts the porosity for the four models with low velocity of inlet fluid (water) velocity, the values of porosity are close $(\varepsilon \approx 0.59)$ for the fluidized bed. The values of porosity are increase according to the model of porosity with the increases of inlet fluid velocities, where the porosity values of model four (Mod 4) is developed more than the other models. In other hand, the porosity values of model one (Mod1) are less than the other values, because its model are based in general porosity for the fluidized bed.

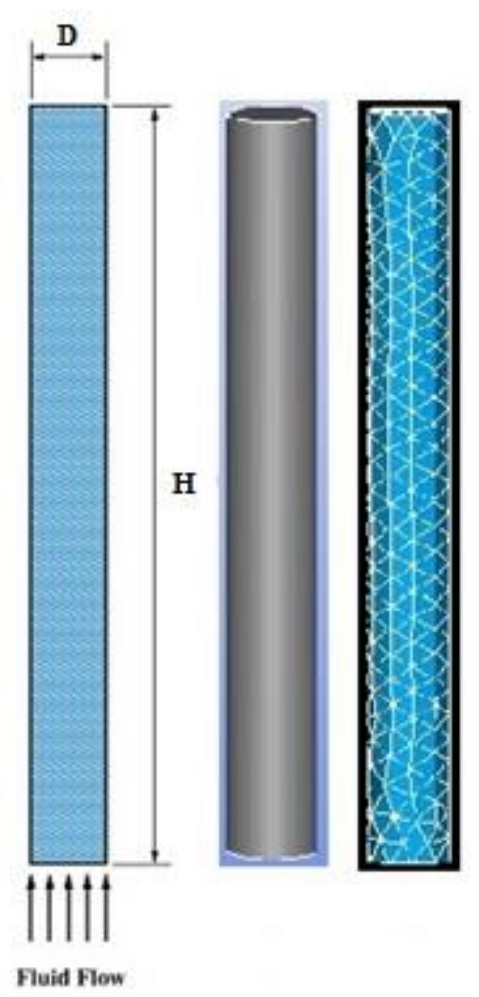

(a) (b) (c)

Figure 4 Sketch of fluidized bed, a) sketch of column, b) geometry 3D, c) meshing

Table 1: Simulation parameters.

\begin{tabular}{|l|c|}
\hline Parameter & Value \\
\hline Particle diameter $[\mathrm{mm}]$ & 2 \\
\hline Number of particles & 2400 \\
\hline Density of particle $\left[\mathrm{kg} / \mathrm{m}^{3}\right]$ & 2300 \\
\hline Young's modulus $[\mathrm{GPa}]$ & 70 \\
\hline Poisson coefficient & 0.35 \\
\hline Coefficient of friction & 0.3 \\
\hline Coefficient of restitution & 0.9 \\
\hline Column diameter $(\mathrm{m})$ & 0.1 \\
\hline Column length $(\mathrm{m})$ & 1 \\
\hline Initial bed height $[\mathrm{m}]$ & 0.1 \\
\hline Porosity initial & 0.4 \\
\hline Density of water $\left[\mathrm{kg} / \mathrm{m}^{3}\right]$ & 1000 \\
\hline Dynamic viscosity of water [Pa.s] & 0.001 \\
\hline DEM time step [s] & $5 \times 10^{-5}$ \\
\hline Simulation time $[\mathrm{s}]$ & 10 \\
\hline
\end{tabular}



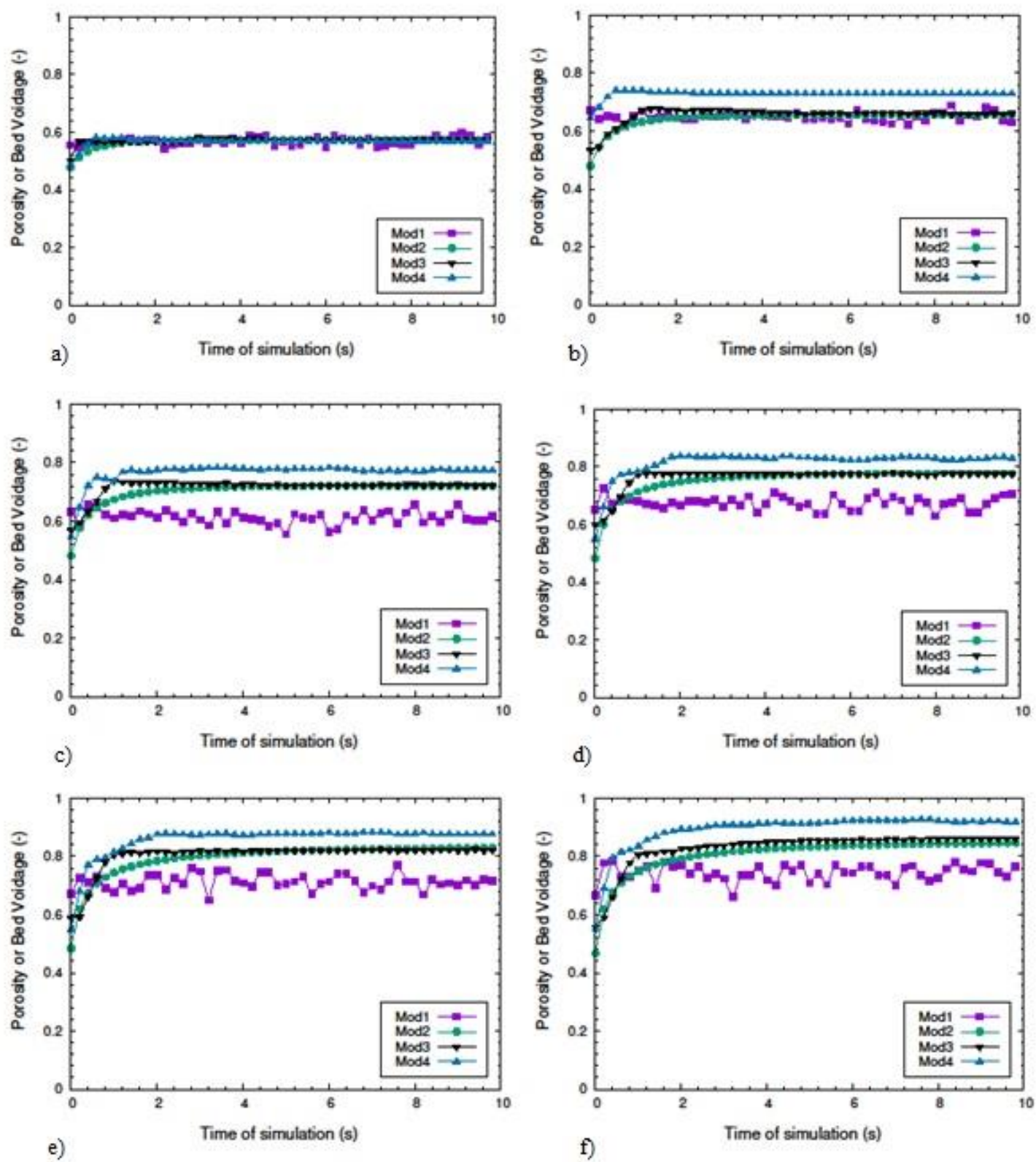

Figure 5 Variation of porosity for the four models with the time of simulation, for inlet water velocity; a) $v_{f}=0.04$, b) $v_{f}=0.06$, c) $v_{f}=0.08$, d) $v_{f}=0.10$, e) $v_{f}=0.12$, and f) $v_{f}=0.14 \mathrm{~m} / \mathrm{s}$.

\subsection{Bed height}

Figure 6 is revealed the relation between the bed height (normalized bed heights) and the inlet liquid velocity. Comparison with the experimental results [35], we seek to find the appropriate model of porosity. Figure 6 reveals that the bed height increase for three models (Mod 2, Mod 3 and Mod 4) with increase the inlet liquid velocity. The figure 6 shows that the Mod 4 results are the closest to the experimental results. Figure 7 (a-f), depicts the bed height of fluidized bed for the four models of porosity as a function of time of simulation. The bed height is developed and increased with the increase of inlet liquid velocity. Bed height values for model four (Mod4) are greater than the rest of the values for other models developed and increased with the increase of inlet liquid velocity (Figure 7-f).

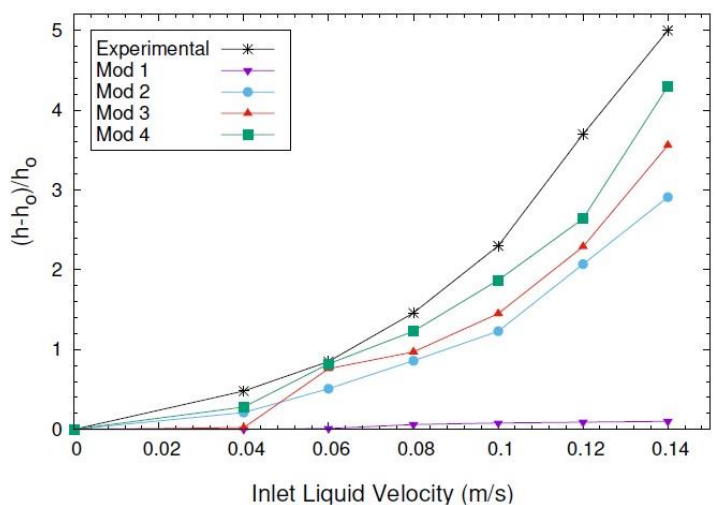

Figure 6 Normalized bed heights versus inlet liquid velocity. 

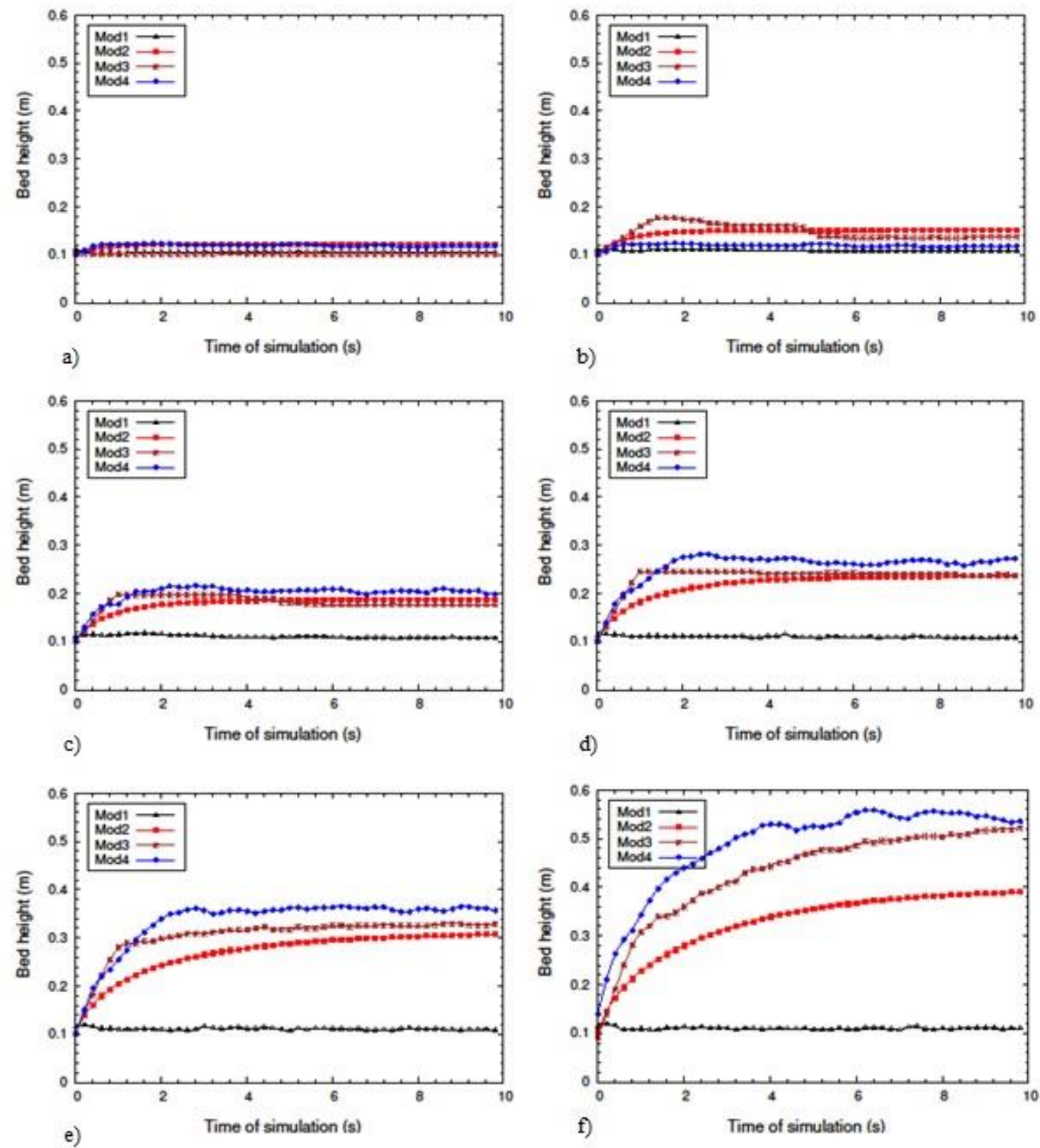

Figure 7 Variation of bed height for the four models with the time of simulation, for inlet liquid velocity, a) $v_{f}=0.04$, b) $v_{f}=0.06$, c) $v_{f}=0.08$, d) $v_{f}=0.10$, e) $v_{f}=0.12$, and f) $v_{f}=0.14 \mathrm{~m} / \mathrm{s}$.

While the bed height values for model 1 (Mod1) are not developed and the particles are still in the base of the column. Figure 8 shows the snapshots of fluidized beds for the four models, at inlet liquid velocity $\left(v_{f}=0.14 \mathrm{~m} / \mathrm{s}\right)$ and time 10 second. The visualization of fluidization process revealed the fact that models (Mod 1 and Mod 2) are efficient to present the movement and position of the particles. The porosity model of Mod 1 and Mod 2 are based on the macroscopic scale (general porosity of the bed). While the third model (Mod 3) is more efficient as compared with first and second models, because it based on the microscopic scale (level of the elements of the meshing). The fourth model (Mod 4) is based on the microscopic scale (level of individual particles and formation of clusters), which make Mod 4 is most reliable between all the models of porosity. All of these reasons makes the Mod 4 is the nearest to the actual fluidized beds in fluidization process. The comparison between the two models; model 3 and model 4 can be done at the level of clusters formation as shown in figure 9. The hydrodynamics of the suspended particles in multi phase flows system, depend on the drag force is the only source which raises the relative motion between particles. The porosity calculation (porosity model), and porosity function effect directly on the magnitude of drag force (Eq.5), which reveal the difference in the hydrodynamic behavior (cluster formation) of the two models (Mod3 and Mod4), the results of this work are consistency with these studies [9, 16, 28, 29, and 44]. 


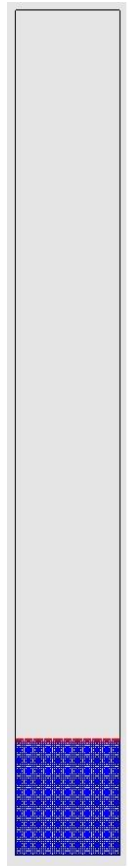

Initial

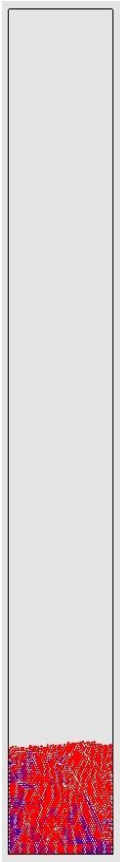

Mod 1

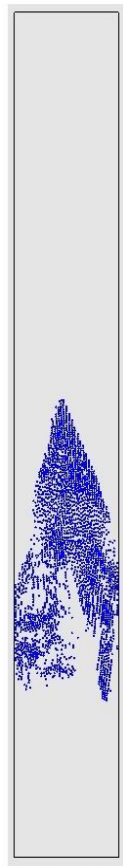

$\operatorname{Mod} 2$

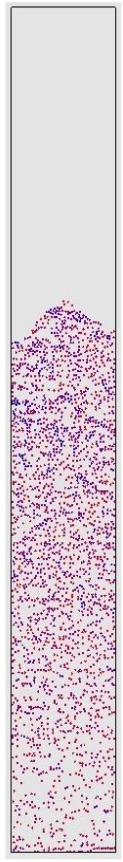

$\operatorname{Mod} 3$

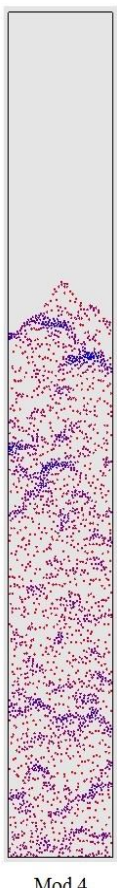

Mod 4

Figure 8 Fluidized beds for the four models of porosity at the end of simulation $\left(\mathrm{t}=10 \mathrm{~s}\right.$ with $\left.v_{f}=0.14 \mathrm{~m} / \mathrm{s}\right)$.

\subsection{Fluidized beds test for Model 4}

The bed being initially at rest at $t=0$, the introduction of the fluid causes the particles to fluidize preferably in the column, as can be seen in Fig. 10 at times $t=0.5 \mathrm{~s}$, and $t$ $=1 \mathrm{~s}$. The expansion of the bed is maximal at $\mathrm{t}=6 \mathrm{~s}$ approximately, before the fluidized bed drops off slightly.

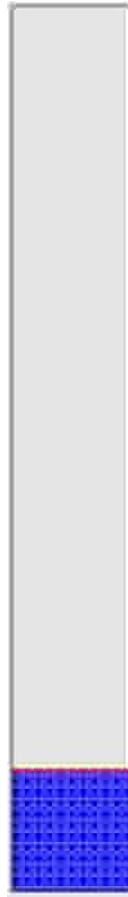

Initial

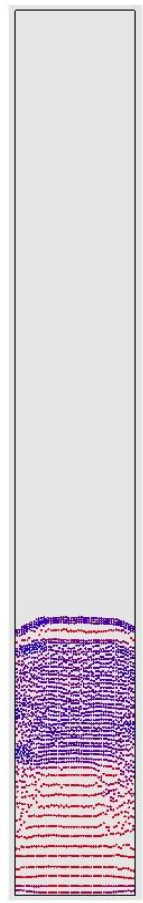

$\mathrm{t}=0.5 \mathrm{~s}$

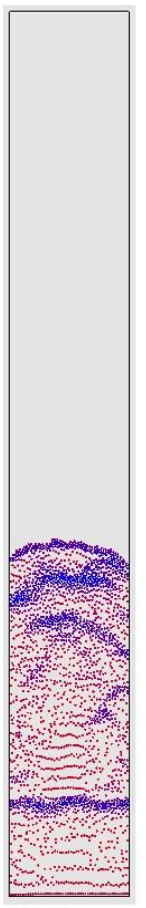

$\mathrm{t}=1 \mathrm{~s}$

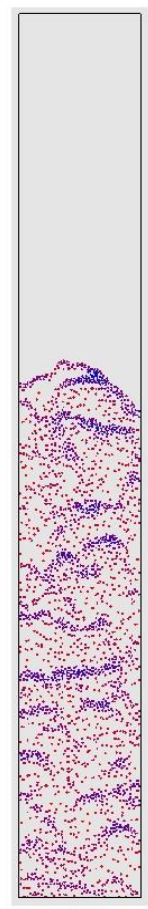

$\mathrm{t}=3 \mathrm{~s}$

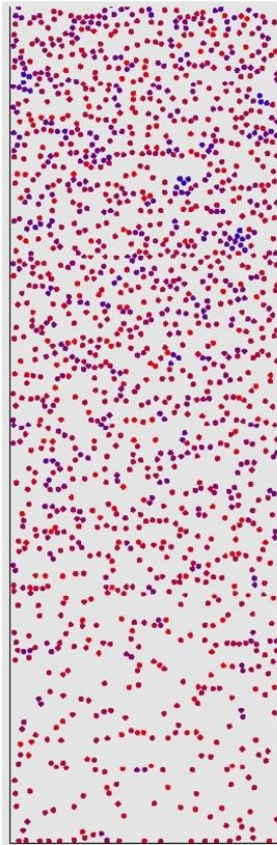

$\operatorname{Mod} 3$

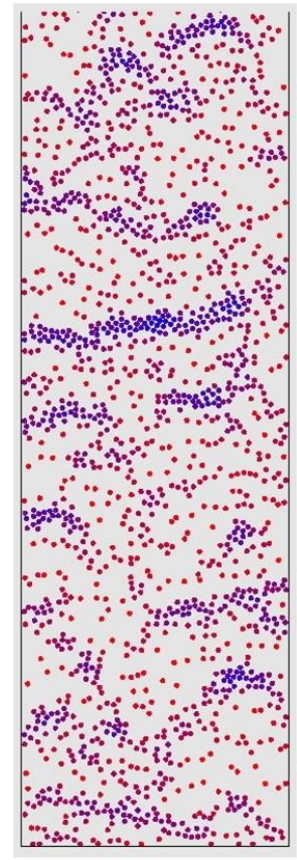

$\operatorname{Mod} 4$

Figure 9 Comparison between two snapshots of model 3 and model 4

The results are very strongly dependent on the porosity function, which requires us to verify the validity of the porosity model 4 (Eq. 14). Fig.10 shows a heterogeneity of the particle distribution in the chamber (for $\mathrm{t}=6 \mathrm{~s}, \mathrm{t}=$ $8 \mathrm{~s}$ and $\mathrm{t}=10 \mathrm{~s}$ ) that can be related to cluster formation.

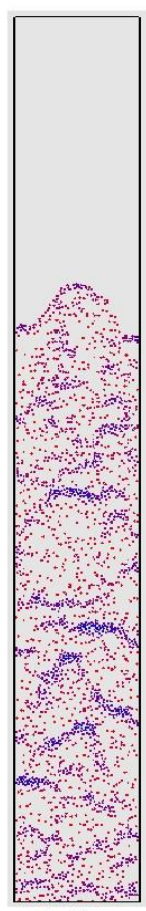

$t=6 s$

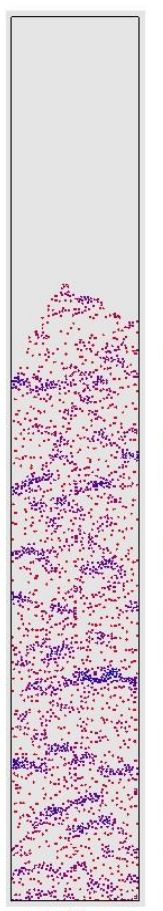

$t=8 \mathrm{~s}$

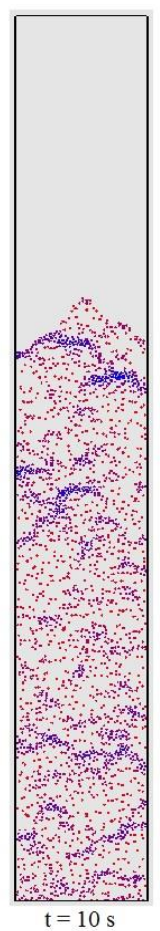

Figure 10 Position of fluidized particles over time $(\mathrm{t}=0-10 \mathrm{~s})$ for porosity model 4 with $v_{f}=0.14 \mathrm{~m} / \mathrm{s}$. 


\section{CONCLUSION}

Four models of porosity have been investigated and compared. The study has been done through an approach based on combine discrete-continuum to achieve the simulations. The results of the comparisons and validation of the four models of porosity revealed a good consistency with the experimental results. The simulations results revealed that the model of porosity (Mod 4), which based on the microscopic scale, is most reliable between all the models of porosity. In the longer term, models of heat transfer and transfer of material between the fluid and the particles (e.g. during a drying operation) will be integrated into the software. This will provide a multi-physical code combining fluid and granular aspects, heat exchanges, material exchanges, inter-particle cohesion and grinding. The applications are as much in the process industries (reactors, dryers) as on larger scale (wave effect on the rock fill structures ...).

\section{Nomenclatures}

$m$ mass of particle, $\mathrm{kg}$

$r$ radius of particle, $\mathrm{m}$

$d$ diameter of particle, $\mathrm{m}$

$a_{j}$ radius for the particle $j(\mathrm{~m})$

$D$ diameter of column, $\mathrm{m}$

$V$ volume, $\mathrm{m}^{3}$

g acceleration due to gravity, $\mathrm{m} / \mathrm{s}^{2}$

$t$ time, s

$n$ normal unit vector, dimensionless

$v$ velocity, $\mathrm{m} / \mathrm{s}$

I moment of inertia of a particle, $\mathrm{kg} \cdot \mathrm{m}^{2} / \mathrm{rad}^{2}$

$T$ Torque, N.m

$p$ pressure, $\mathrm{N} / \mathrm{m}^{2}$

$C_{D}$ drag force coefficient, dimensionless

$F_{\text {ext }}$ external force, $\mathrm{N}$

$R^{\alpha}$ internal force, $\mathrm{N}$

$F_{C}$ contact force, $\mathrm{N}$

$F_{t}$ tangential force (frictional force), N

$F_{n}$ normal force, $\mathrm{N}$

$F_{D}$ drag force, $\mathrm{N}$

$F_{B}$ float (buoyant) force, $\mathrm{N}$

$f$ gravity force, $\mathrm{N}$

ne number of nodes

$N_{b}$ number of contacts

Re Reynolds number, dimensionless

\section{Greek letters}

$\rho$ density, $\mathrm{kg} / \mathrm{m}^{3}$

$\tau$ viscous stress tensor, $\mathrm{Pa}$

$\varepsilon$ porosity (void fraction), dimensionless

$\mu$ viscosity, Pa.s

$\omega$ angular velocity of a particle, $\mathrm{rad} / \mathrm{s}$

$\chi$ empirical coefficient, dimensionless

$\varphi_{j}$ basic functions, dimensionless

\section{Subscripts}

$\chi$ empirical coefficient, dimensionless

$f$ fluid (liquid) phase

$i$ for $i$ th particles (solid phase)

$p$ particle

\section{REFERENCE}

[1] G. L. Matheson, W. A. Herbst and P. H. Halt, "Characteristics of Fluid-Solid Systems," Industrial Engineering Chemical, (41), pp.1099, 1949.

[2] E. Hartge and J. Werther, "Analysis of the local structure of the two-phase flow in a fast fluidized bed. In, Circulating Fluidized Bed Technology," Chemical Engineering Technology, (58), pp. 688, 1986.

[3] C. BAILIE, LIANG-TSENG FAN, J. STEWART, "Instability of Fluidized Beds," Chemical Engineering, (6), 3, pp. 469-473, 1961.

[4] P. J. Bakker and P. M. Heertjes, "Porosity distributions in a fluidized bed," Chemical Engineering Science, (12), 4, pp. 260-271, 1960.

[5] G. Delmon, R. Faure., B. de Gasquet, G. Giraud, J.P. Clerc, "Measurement of voidage in a fluidized bed using a capacitive sensor," Powder Technology, (86), pp. 149-153, 1996.

[6] E. W. Grohse, "Analysis of gas fluidized solid systems by X-ray absorption, “AIChE Journal, (1), pp. 358, 1955.

[7] R. N. Bartholomew, R. M. Casagrande, "Measuring Solids Concentration in Fluidized Systems by Gamma-Ray Absorption," Industry Engineering Chemical, (49), 3, pp. 428-431, 1957.

[8] R. H. Hunt, W. R. Biles and CO. Reed, "Final catalyst density with radioisotopes," Petroleum Refiner, (36), pp. 179, 1957.

[9] D. Gidaspow, C. Lin and Y. C. Seo, "Fluidization in Two-Dimensional Beds with a Jet. 1. Experimental Porosity Distribution," Industrial Engineering Chemical Fundamentals, (22), pp. 187-193, 1983.

[10] J. X. Bouiiiard, R. W. Lyczkowski and D. Gidaspow, "Porosity distributions in a fluidized bed with an immersed obstacle," AIChE Journal, (35), 6, pp. 908-922, 1989.

[11] L S. Fan, "Development of an optical fiber probe for solids holdup measurement in a fluidized bed," report AC22-85PC81520, Ohio State University Research Foundation, USA, 1986.

[12] P. L. Yue, "Bubble phase voidage and dense phase voidage in thin two-dimensional fluidized beds," Chemical Engineering Science, (41), 1, pp. 171177, 1986.

[13] J.-S. Yang, Y. A. Liu and A. M. Squires, “A simple light-probe method for quantitative measurements of particle volume-fractions in fluidized beds," Powder Technology, (49), 2, 177-187, 1987.

[14] J.F. Richardson, W.N. Zaki, "Sedimentation and fluidization," Transactions of the Institution of Chemical Engineers, (32), pp. 35-53, 1954. 
[15] C.Y. Wen, Y.H. Yu, "Mechanics of fluidization," Chemical Engineering Progress Symposium Series, (62), pp. 100-111, 1966.

[16] J. A. M. Kuipers, H. Tammes, W. Prins and W. P. M. van Swaaij, "Experimental and theoretical porosity profiles in a two-dimensional gas-fluidized bed with a central jet," Powder Technology, (71), pp. 87-99, 1992.

[17] K.E. Campos-Díaz , E.R. Bandala-González, R. Limas-Ballesteros, "Fluid bed porosity mathematical model for an inverse fluidized bed bioreactor with particles growing bio-film," Journal of Environmental Management, (104), pp. 62-66, 2012.

[18] D. Gidaspow and B. Ettehadieh, "Fluidization in two-dimensional beds with a jet. 2, Hydrodynamic modeling," Industrial Engineering Chemical Fundamentals, (22), 2, pp. 193-201, 1983.

[19] J. X. Bouillard, R. W. Lyczkowski, S. Folga, D. Gidaspow and G. F. Berry, "Hydrodynamics of erosion of heat exchanger tubes in fluidized bed combustors," Canadian journal Chemical Engineering, (67), pp. 218-229, 1989.

[20] J. Yang, A. Renken, "A generalized correlation for equilibrium of forces in liquid-solid fluidized bed," Chemical Engineering Journal, (92), pp. 7-14, 2003.

[21] O. Akgiray, E. Soyer, "An evaluation of expansion equation for fluidized solid-liquid systems," Journal of Water Supply: Research and Technology-AQUA, (55), pp. 517-526, 2006.

[22] T. Renganathan, K. Krishnaiah, "Spatio-temporal evolution of void fraction in liquid-solid inverse fluidized bed," Chemical Engineering Science (62), 1-2, pp. 328-338, 2007.

[23] M. Fuentes, J.N. Scena, A.P. Aguirre, M.C. Mussati, "Hydrodynamic aspects in anaerobic fluidized bed reactor modeling," Chemical Engineering and Processing, (47), pp. 1530-1540, 2008.

[24] E. Soyer, O. Akgiray, "A new simple equation for the prediction of filter expansion during back washing," Journal of Water Supply: Research and Technology-AQUA, (58), pp. 336-345, 2009.

[25] W.F. Ramirez, K.P. Galvin, "Dynamic model of multi-species segregation and dispersion in liquid fluidized beds," AIChE Journal, (51), 7, pp. 21032108, 2005.

[26] T. Tanaka, S. Yonemura, K. Kiribayashi, Y. Tsuji, "Cluster Formation and Particle-Induced Instability in Gas-Solid Flows Predicted by the DSMC Method," JSME International Journal, Ser. B, (39), 2, pp. 239-245, 1996.

[27] E. Helland, R. Occelli, L. Tadrist, "Numerical study of cohesive powders in a dense fluidized bed," C.R. Academic Science Paris, t.327, Série IIb, Computational fluid mechanics, pp. 1397-1403, 1999.

[28] E. Helland, R. Occelli, L. Tadrist, "Numerical study of cluster formation in a gas-particle circulating fluidized bed," Powder Technology, (110), pp. 210221,2000
[29] E. Helland, R. Occelli, L. Tadrist, "Computational study of fluctuating motions and cluster structures in gas-particle flows," International Journal of Multiphase Flow, (28), pp. 199-223, 2002.

[30] E. Helland, H. Bournot, R. Occelli, L. Tadrist," Drag reduction and cluster formation in a circulating fluidized bed," Chemical Engineering Science. (62), pp. 148-158, 2007.

[31] C.H. Ibsen, E. Helland, B.H. Hjertager, T. Solberg, L. Tadrist, R. Occelli, "Comparison of multifluid and discrete particle modeling in numerical predictions of gas particle flow in circulating fluidized beds," Powder Technology, (149), pp. 2941, 2004.

[32] S. Al-Arkawazi, "Simulation the hydrodynamic behavior of binary solid-liquid fluidized beds," Journal of Materials and Environmental Sciences (8), 7, pp. 2522-2529, 2017.

[33]Z. Qinghong , W. Shuyan , L. Huilin, L. Guodong, W. Shuai, Z. Guangbo, "A coupled Eulerian fluid phase-Eulerian solids phase-Lagrangian discrete particles hybrid model applied to gas-solids bubbling fluidized beds," Powder Technology, (315), pp. 385-397, 2017.

[34] A. Esteghamatian, A. Hammouti, M. Lance, and A. Wachs, "Particle resolved simulations of liquid/solid and gas/solid fluidized beds," Physics of Fluids, (29), pp. 033302-14, 2017.

[35] S. Al-Arkawazi, C. Marie, K. Benhabib, and P. Coorevits, "Modeling the hydrodynamic forces between fluid-granular medium by coupling DEMCFD," Chemical Engineering Research and Design, (117), pp. 439-447, 2017.

[36] G. de Saxcé, Z.-Q. Feng, "The bipotentiel method: a constructive approach to design the complete contact law with friction and improved numerical algorithms," Mathematical and Computer Modelling, (28), pp. 225-245, 1998.

[37] J. Fortin, P. Coorevits, "Selecting contact particles in dynamics granular mechanics systems," Journal Applied Mathematics and Computation, (168), pp. 207-213, 2004.

[38]M. Jean, "The non-smooth contact dynamics method," Computer Methods in Applied Mechanics and Engineering, (177), pp. 235-257, 1999.

[39] J.-J. Moreau, "Some numerical methods in multibody dynamics: application to granular materials," Europe Journal Mechanic, A/Solids., (13), pp. 93-114, 1994.

[40]R. Di Felice, "The voidage function for fluidparticle interaction systems," Int. J. Multiphase Flow, (20), 1, pp. 153-159, 1994

[41] P. Brown, D. Lawler, D., "Sphere drag and settling velocity revisited," J. Environ. Eng., (129), 3, pp. 222-231, 2003.

[42]F. Archambeau, N. Méchitoua, M. Sakiz, "Code Saturne: a finite volume method for the computation of turbulent incompressible flowsindustrial applications," International Journal Finite Volume, (1), 1, pp. 1-62, 2004. 
[43]F. Zhou, S. Hu, Y. Liu, C. Liu, and T. Xia, "CFDDEM simulation of the pneumatic conveying of fine particles through a horizontal slit," Particuology, (16), pp.196-205, 2014.

[44] S. D. Kim,Yo H. Kim, S. A. Roh and D. H. Lee, "Solid Circulation Characteristics in an Internally Circulating Fluidized Bed with Orifice-Type Draft Tube," Korean Journal Chemistry Engineering, (19), 5, pp. 911-916, 2002. 